\title{
Konstruksi Fungsi Lyapunov untuk Menentukan Kestabilan
}

\author{
Reni Sundari dan Erna Apriliani \\ Jurusan Matematika, Fakultas Matematika dan Ilmu Pengetahuan Alam, \\ Institut Teknologi Sepuluh Nopember (ITS) \\ Jl. Arief Rahman Hakim, Surabaya 60111 Indonesia \\ e-mail: april@matematika.its.ac.id
}

\begin{abstract}
Abstrak-Fungsi Lyapunov adalah salah satu fungsi yang dikonstruksi untuk memeriksa kestabilan global dari suatu sistem nonlinier. Pada penelitian ini digunakan metode Variabel Gradien, Kravoskii dan Energi Casimir dalam mengkonstruksi fungsi Lyapunov. Berdasarkan hasil perhitungan dan simulasi yang dilakukan menggunakan metode variabel gradien dan metode Energi Casimir diperoleh fungsi Lyapunov untuk sistem Lorenz pada semua titik kesetimbangan. Sedangkan metode Kravoskii belum menghasilkan fungsi Lyapuno untuk sistem Lorenz pada semua titik kesetimbangan.
\end{abstract}

Kata Kunci-Fungsi Lyapunov, Variabel Gradien, Krasovkii, Energi-Casimir, Sistem Lorenz.

\section{PENDAHULUAN}

$\mathrm{M}$ ATEMATIKA merupakan disiplin ilmu yang dapat diterapkan dalam berbagai ilmu pengetahuan dan dapat memberikan interpretasi solusi analitis yang lebih rinci. Permasalahan yang terjadi dalam kehidupan seharihari kebanyakan merupakan sistem dinamik. Sistem dinamik yaitu suatu sistem persamaan yang dipengaruhi oleh perubahan gerak dan waktu. Salah satu kajian penting dalam permasalahan sistem dinamik yakni bagaimana keadaan sistem, apakah sistem tersebut merupakan sistem yang stabil atau tak stabil.

Aleksander Mikhailovich Lyapunov dalam tesisnya yang berjudul A general task about the stability of motion mengembangkan dua metode untuk menganalisis kestabilan dari suatu kesetimbangan, yang dikenal dengan metode Lyapunov langsung (The Second Method of Lyapunov) dan metode Lyapunov tak langsung (First Method).

Penyelesian kestabilan sistem dinamik dengan metode Lyapunov langsung mensyaratkan suatu fungsi, yang disebut sebagai fungsi Lyapunov. Yaitu fungsi skalar yang memenuhi beberapa syarat diantaranya jika ada sebuah fungsi definit positif sedemikian sehingga turunan dari yaitu semidefinit negatif [1]. Metode Lyapunov langsung banyak diterapkan untuk menganalisis kestabilan baik sistem linier maupun sistem nonlinier, sistem time-invariant dan juga sistem time-varrying.

Pada penelitian ini dibahas mengenai mengkonstruksi fungsi Lyapunov untuk menganalisis kestabilan pada sistem nonlil-nier dengan menggunakan metode variabel gradien, metode Krasovkii, dan metode Energi-Casimir dan hasil konstruksi fungsi Lyapunov akan diterapkan pada contohcontoh sistem dinamik nonlinier yaitu sistem Lorenz.

\section{DASAR TEORI}

\section{A. Sistem Lorenz}

Sistem persamaan diferensial biasa dari sistem Lorenz sebagai berikut:

$$
\begin{gathered}
\frac{d x}{d t}=\sigma(y-x) \\
\frac{d y}{d t}=r x-y-x z \\
\frac{d z}{d t}=x y-\beta z
\end{gathered}
$$

Keadaan atmosfer dalam model ini dapat digambarkan secara utuh dengan tiga buah variabel bergantung waktu yaitu: laju konveksi $x$, distribusi temperature horizontal $y$, dan distribusi temperature vertikal $z$, dengan tiga parameter yang menjelaskan karakter dari model tersebut yaitu: $\sigma$ (rasio viskositas tehadap konduktivitas termal), $r$ (perbedaan temperature antara bagian atas dan bagian bawah lapisan), dan $\beta$ (perbandingan luas dan ketebalan.

\section{B. Kestabilan dan Titik Kesetimbangan}

Setiap sistem memiliki keadaan setimbang yang berbedabeda. Keadaan setimbang suatu sistem dapat terjadi pada suatu titik yang disebut titik kesetimbangan. Titik kesetimbangan adalah suatu titik saat sistem tidak mengalami perubahan sepanjang waktu. Sebuah titik $x_{e} \in$ $\mathbb{R}^{n}$ adalah sebuah titik kesetimbangan dari sistem persamaan diferensial $\dot{x}=f(x)$ jika memenuhi $f\left(x_{e}\right)=0$.[5]

\section{Fungsi Lyapunov}

Fungsi Lyapunov adalah suatu fungsi yang memenuhi tiga pernyataan berikut ini.

Definsi 2.1 [6] Diberikan fungsi $V: \mathcal{D} \in \mathbb{R}^{n}>\mathbb{R}$ dan $x_{e} \in$ $\mathcal{D}$ titik kesetimbangan sistem persamaan diferensial nonlinier. Fungsi $V$ disebut fungsi Lyapunov jika memenuhi pernyataan berikut:

a. Fungsi $V$ kontinu dan mempunyai turunan parsial pertama yang kontinu pada $\mathcal{D}$.

b. Fungsi $V(x)>0$ untuk $x \in \mathcal{D}$ dengan $x \neq x_{e}$ dan $V\left(x_{e}\right)=0$ dengan $x=x e$ (dengan titik kesetimbangan $x_{e}$ merupakan titik minimum global).

c. Fungsi $\dot{V}(x) \leq 0$ untuk setiap $x \in \mathcal{D}$.

\section{Metode Variabel Gradien}

Diberikan $V: \mathcal{D} \rightarrow \mathbb{R}$ adalah fungsi diferensial kontinu 
dan $g(x)=\left(\frac{\partial V}{\partial x}\right)^{T}$. Derivatif dari $V(x)$ sepanjang trayektori diberikan oleh

$V(x)=\sum_{i=1}^{n} \frac{\partial V}{\partial x_{i}} \dot{x}_{i}=\int_{0}^{1} \frac{d\left(\sigma g_{i}(\sigma x)\right)}{d \sigma} d \sigma=g_{i}(x)$

Kemudian, mengkonstruksi $g(x)$ sedemikian sehingga $g(x)$ adalah gradien dari fungsi definit positif dan $\dot{V}(x)=$ $g^{T}(x) f(x)<0, x \in \mathcal{D}, x \neq 0$. Fungsi $V(x)$ bisa dihitung dengan integral

$$
V(x)=\int_{0}^{1} g^{T}(\sigma x) x d \sigma=\int_{0}^{1} \sum_{j=1}^{n} g_{j}(\sigma x) x_{j} d \sigma
$$

\section{E. Metode Kravoskii}

Proposisi 2.2 Fungsi $f, g: \mathbb{R}^{n} \rightarrow \mathbb{R}^{n}$ adalah fungsi diferensial kontinu sedemikian sehingga $f(0)=0$. Maka untuk setiap $x \in \mathbb{R}^{n}$ terdapat $\alpha \in[0,1]$ sedemikian sehingga

$$
g^{T}(x) f(x)=g^{T}(x) \frac{\partial f}{\partial x}(\alpha x) x
$$

Teorema 2.2 (Teorema Krasovskii) Diberikan $x(t)=0$ adalah titik kesetimbangan untuk system dinamika nonlinier

$$
\dot{x}(t)=f(x(t)), x(0)=x_{0}, t \geq 0
$$

Dimana $f: \mathcal{D} \rightarrow \mathbb{R}^{n}$ adalah diferensial kontinu dan $D$ adalah himpunan buka dengan $0 \in \mathcal{D}$. Diasumsikan terdapat matrik definit positif $P \in \mathbb{R}^{n x n}$ dan $R \in \mathbb{R}^{n x n}$ sedemikian

$$
\left[\frac{\partial f}{\partial x}(x)\right]^{T} P+P\left[\frac{\partial f}{\partial x}(x)\right] \leq-R, \quad x \in \mathcal{D}, x \neq 0
$$

Maka solusi nol $x(t)=0$ adalah kesetimbangan tunggal stabil asymptotis dengan fungsi lyapunov $V(x)=$ $f^{T}(x) P f(x)$. Jika $\mathcal{D} \equiv \mathbb{R}^{n}$, maka solusi nol $x(t)=0$ adalah ketimbangan tunggal stabil asymptotis global.

\section{F. Metode Energi Casimir}

Diberikan fungsi $C: \mathcal{D} \rightarrow \mathbb{R}$ dan didefinisikan

$$
(x) \cong \sum_{i=1}^{r} \mu_{i} C_{i}(x)
$$

Untuk $\mu_{i} \in r, i=1, \ldots, r$.

Teorema 2.3 (Teorema Energi-Casimir) dengan menganggap sistem dinamika nonlinier dimana $f: \mathcal{D} \rightarrow \mathbb{R}^{n}$ adalah lipschitz kontinu pada $\mathcal{D}$. Diberikan $x_{e} \in \mathcal{D}$ adalah titik kesetimbangan dari suatu sistem dan diberikan $C_{i}: \mathcal{D} \rightarrow$ $\mathbb{R}, i=1, \ldots, r$ menjadi fungsi Casimir. Diasumsikan bahwa vektor $C_{i}{ }^{\prime}\left(x_{e}\right), i=2, \ldots, r$ adalah bebas linier dan andaikan terdapat $\mu=\left[\mu_{1}, \ldots, \mu_{r}\right]^{T} \in \mathbb{R}^{r}$ sedemikan hingga $\mu_{1} \neq$ $0, E^{\prime}\left(x_{e}\right)=0 \quad$ dan $\quad x^{T} E^{\prime \prime}\left(x_{e}\right) x>0, x \in \mathcal{M}$, $\operatorname{dimana} \mathcal{M} \triangleq\left\{x \in \mathcal{D}: C_{i}{ }^{\prime}\left(x_{e}\right) x=0, i=2, \ldots r\right\}$.

Maka terdapat $\alpha \geq 0$ sedemikian sehingga

$$
E^{\prime \prime}\left(x_{e}\right)+\alpha \sum_{i=2}^{r}\left(\frac{\partial C_{i}}{\partial x}\left(x_{e}\right)\right)^{T}\left(\frac{\partial C_{i}}{\partial x}\left(x_{e}\right)\right)>0
$$

Kemudian, solusi kesetimbangan $x(t) \equiv x_{e}$ dari sistem dinamika nonlinier adalah stabil lyapunov dengan fungsi lyapunov.

$$
V(x)=E(x)-E\left(x_{e}\right)+\frac{\alpha}{2} \sum_{i=2}^{r}\left[C_{i}(x)-C_{i}\left(x_{e}\right)\right]^{2}
$$

\section{PEMBAHASAN}

\section{A. Titik Kesetimbangani}

Jika $r>1$ maka terdapat dua titik kesetimbangan yaitu $(\sqrt{b(r-1)}, \sqrt{b(r-1)}, r-1)$ dan $(-\sqrt{b(r-1)},-\sqrt{b(r-1)}, r-1), \quad$ sedangkan $\quad r<1$ terdapat satu titik kesetimbangan yaitu pada titik $(0,0,0)$.

\section{B. Kestabilan Lokal}

Metode yang digunakan untuk mentransformasi sistem nonlinier menjadi sistem linier adalah metode matrik Jacobi.

Matrik Jacobi yang dibentuk dari sistem diatas adalah

$$
J=\left[\begin{array}{ccc}
-\sigma & \sigma & 0 \\
r-z & -1 & -x \\
y & x & -b
\end{array}\right]
$$

Titik kesetimbangan nol $T_{1}=(0,0,0)$, diperoleh persamaan karakteristik yaitu

$$
(\lambda+b)\left(\lambda^{2}+(\sigma+1) \lambda+\sigma(1-r)\right)=0
$$

Karena $b, \sigma$ dan $r$ adalah konstanta positif, maka akar-akar persamaan karakteristik yang diperoleh adalah $\lambda_{1}=$ $-b, \lambda_{2,3}=-\frac{1}{2}(\sigma+1) \pm \frac{1}{2} \sqrt{\sigma^{2}-(2+4 r) \sigma+1}$.

Untuk $r<1$, kondisi didalam akar kuadrat kurang dari $(\sigma-1)^{2}$, menjadikan $\lambda<0$ sehingga nilai eigen bernilai negatif dan riil. Oleh karena itu, titik kesetimbangan pada titik $(0,0,0)$ bersifat stabil.

Sedangkan pada dua titik yang lain $\left(T_{2}\right.$ dan $\left.T_{3}\right)$, persamaan karakteristik yang didapatkan yaitu

$\lambda^{3}+(b+\sigma+1) \lambda^{2}+(\sigma b+b r) \lambda+2 b \sigma(r-1)=0$

Dengan menggunakan Routh-Hurwitz, maka dua titik kesetimbangan jika $1<r<\frac{\sigma(\sigma+b+3)}{\sigma-b-1}$,maka $T_{2,3}=$ $( \pm \sqrt{b(r-1)}, \pm \sqrt{b(r-1)}, r-1)$ bersifat stabil.

\section{Metode Variabel Gradien}

Dengan dimisalkan

$$
\nabla V(x)=\left[\begin{array}{lll}
h_{11} x & h_{12} y & h_{13} z \\
h_{21} x & h_{22} y & h_{23} z \\
h_{31} x & h_{32} y & h_{33} z
\end{array}\right]
$$

Maka fungsi Lyapunov adalah

1. Titik Kesetimbangan nol

Fungsi Lyapunov yang diperoleh

$$
\begin{aligned}
V=\int_{0}^{1} \nabla V(x) d x \\
=\int_{0}^{1} \gamma\left(x^{2}+y^{2}-0,3 z^{2}+y z\right) d \gamma \\
=\frac{1}{2}\left(x^{2}+y^{2}-0,3 z^{2}+y z\right)
\end{aligned}
$$

2. Titik Kesetimbangan pada dua titik yang lain

$$
\begin{aligned}
V= & \frac{1}{2}\left(\left(x-x^{*}\right)^{2}+\left(y-y^{*}\right)^{2}\right) \\
& \left.-0,3\left(z-z^{*}\right)^{2}+\left(y-y^{*}\right)\left(z-z^{*}\right)\right)
\end{aligned}
$$

\section{Metode Kravoskii}

1. Titik Kesetimbangan nol Titik kesetimbangan yaitu $T_{1}=(0,0,0)$ disubstitusikan ke matriks $J$. Selanjutnya 
mendapatkan matriks $P$ yaitu

$$
P=\left[\begin{array}{ccc}
\frac{10 r-11-r^{2}}{220(r-1)} & \frac{-(r-1)}{22(r-1)} & 0 \\
\frac{-(r-1)}{22(r-1)} & \frac{(r-1)}{22(r-1)} & 0 \\
0 & 0 & \frac{3}{16}
\end{array}\right]
$$

Fungsi Lyapunov adalah

$$
\begin{aligned}
V= & f^{T}(x) P f(x) \\
= & \frac{10 r-11-r^{2}}{220(r-1)}(\sigma(y-x))^{2} \\
& -\frac{2(r-1)}{22(r-1)} \sigma(y-x)(x(r-z)-y) \\
& +\frac{(r-1)}{22(r-1)}(x(r-z)-y)^{2}+\frac{3}{16}(x y-\beta z)^{2}
\end{aligned}
$$

2. Titik kesetimbangan pada $T_{2}=$ $(\sqrt{b(r-1)}, \sqrt{b(r-1)}, r-1)$

Fungsi Lyapunov yang diperoleh

$$
\begin{gathered}
V=0,1346(\sigma(y-x))^{2} \\
+0,3391 \sigma(y-x)(x(r-z)-y) \\
+0,1726 \sigma(y-x)(x y-\beta z) \\
+0,4694(x(r-z)-y)^{2} \\
-0,1026(x(r-z)-y)(x y-\beta z) \\
+0,3381(x y-\beta z)^{2}
\end{gathered}
$$

3. Titik Kesetimbangan

$$
(-\sqrt{b(r-1)},-\sqrt{b(r-1)}, r-1)
$$

$T_{3}=$

Fungsi Lyapunov yang diperoleh

$$
\begin{aligned}
& V=-5, 6421(\sigma(y-x))^{2} \\
&-14,8311 \sigma(y-x)(x(r-z)-y)+11,3256 \sigma(y-x)(x y-\beta z) \\
&-27,2288(x(r-z)-y)^{2} \\
&-11,8564(x(r-z)-y)(x y-\beta z) \\
&-17,2255(x y-\beta z)^{2}
\end{aligned}
$$

\section{E. Metode Energi Casimir}

1. Titik Kesetimbangan nol

Fungsi Lyapunov yang diperoleh

$$
V=\frac{1}{2}\left(x^{2}+y^{2}\right)+\frac{1}{4} y^{4}
$$

2. Titik Kesetimbangan pada dua titik yang lain Fungsi Lyapunov yang diperoleh

$$
\begin{gathered}
V=\frac{b}{2}\left(y^{2}-y^{* 2}\right)+\frac{d}{2}\left(z^{2}-z^{* 2}\right) \\
-\left(y-y^{*}\right)-\left(z-z^{*}\right)+\frac{1}{2} \\
\left(\begin{array}{c}
\left.\frac{d}{2}\left(z^{2}-z^{* 2}\right)\right)^{2} \\
-\left(z-z^{*}\right)
\end{array}\right)
\end{gathered}
$$

Dengan $b= \pm \frac{1}{\sqrt{\beta(r-1)}}$ dan $d=\frac{1}{r-1}$.

\section{SIMULASI DAN ANALISIS}

\section{A. Titik Kesetimbangan nol}

Nilai parameter yang digunakan adalah $\sigma=10, \beta=8 / 3$. Berikut ini adalah hasil penyelesaian dari fungsi Lyapunov beserta turunannya

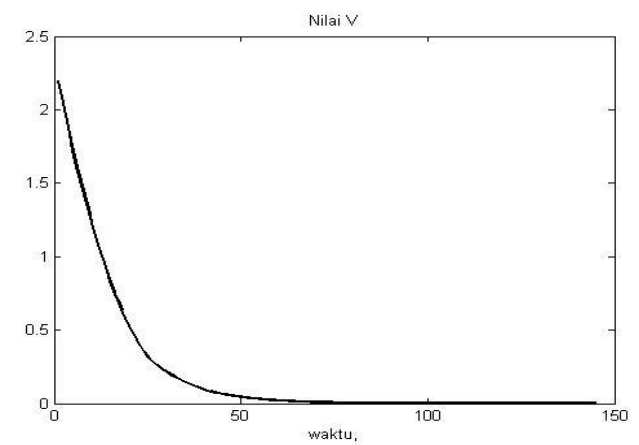

Gambar 1. Grafik Fungsi Lyapunov dengan Metode Variabel Gradien, $r=0.5$

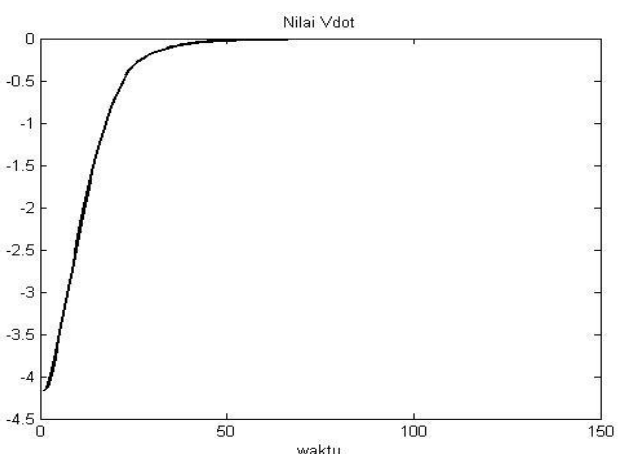

Gambar 2. Grafik Turunan Fungsi Lyapunov

Berdasarkan gambar 1 dan 2, terlihat bahwa fungsi Lyapunov dengan metode variabel gradien semua berada pada nilai positif dan bergerak menuju nol. Dan turunannya dimana semua nilai berada pada bagian negatif dan bergerak menuju titik nol.Hal ini menunjukkan bahwa Fungsi Lyapunov dapat dikonstruksi dengan metode Variabel gradien untuk sistem Lorenz pada titik kesetimbangan nol dengan parameter $\square=0,5$.

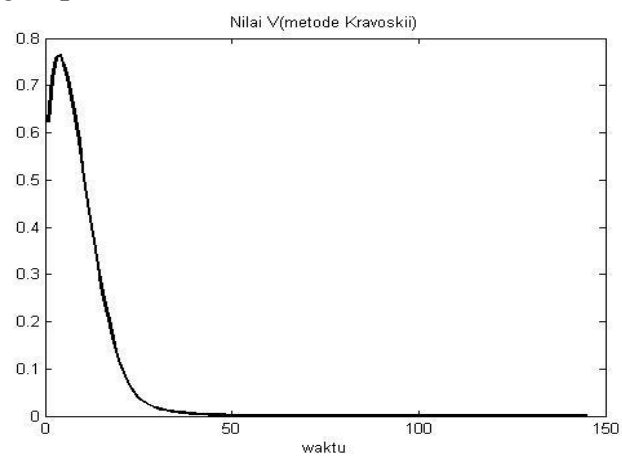

Gambar 3. Grafik Fungsi Lyapunov dengan Metode Kravokii, $r=0,5$ 


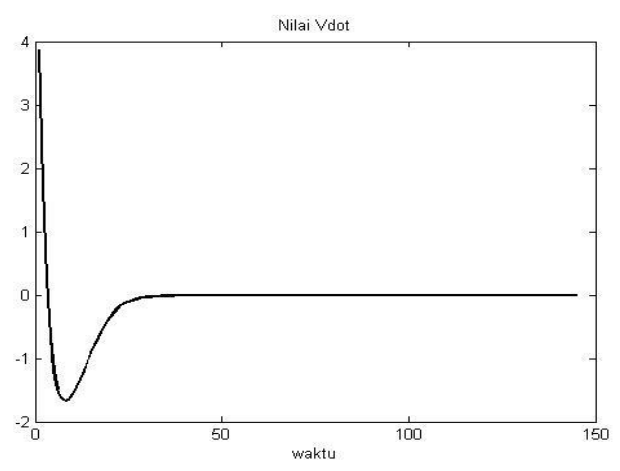

Gambar 4. Grafik Turunan

Berdasarkan gambar 3 dan 4 terlihat bahwa fungsi Lyapunov dengan metode Kravoskii semua berada pada nilai positif dan bergerak menuju nol. Dan turunan dimana sebagian nilai berada pada bagian positif dan sebagian nilai berada pada bagian negatif bergerak menuju titik nol juga.Hal ini menunjukkan bahwa Fungsi Lyapunov tidak dapat dikonstruksi dengan metode Kravoskii untuk sistem Lorenz pada titik kesetimbangan nol dengan parameter $\square<$ 1 .

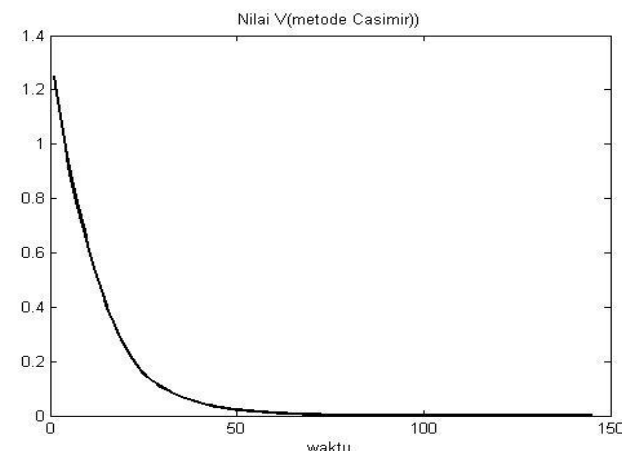

Gambar 5. Grafik Fungsi Lyapunov dengan Metode Energi Casimir

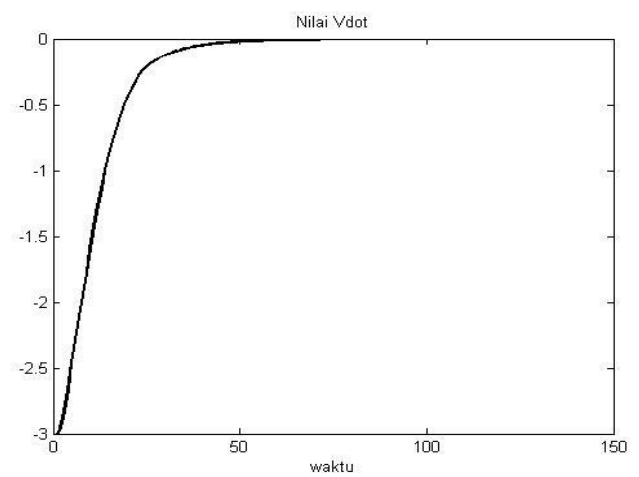

Gambar 6. Grafik Turunannya

Berdasarkan gambar 5 dan 6 terlihat bahwa fungsi Lyapunov dengan metode Energi Casimir semua berada pada nilai positif dan bergerak menuju nol. Dan turunannya dimana semua nilai berada pada bagian negatif dan bergerak menuju titik nol.Hal ini menunjukkan bahwa Fungsi Lyapunov dapat dikonstruksi dengan metode Energi-Casimir untuk sistem Lorenz pada titik kesetimbangan nol dengan parameter $\square=$ 0.5 .
B. Titik Kesetimbangan dua titik yang lain

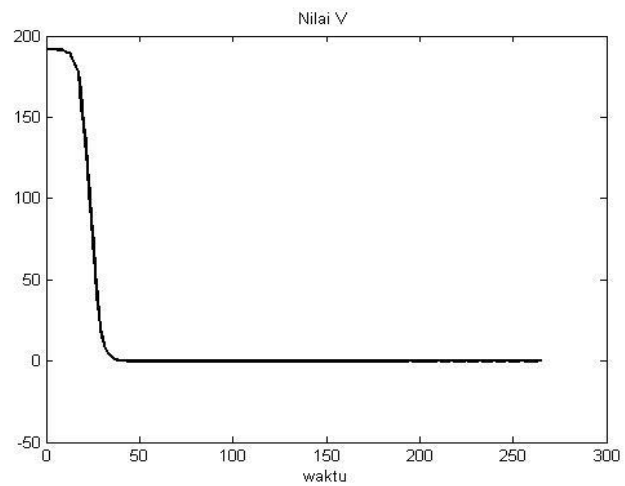

Gambar 7. Grafik Fungsi lyapunov dengan metode Variabel

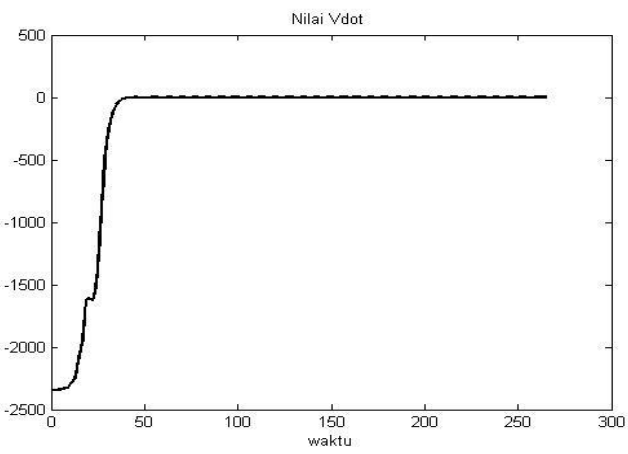

Gambar 8. Grafik turunan dari gambar 7

Berdasarkan gambar 7 dan 8, terlihat bahwa fungsi Lyapunov semua berada pada nilai positif dan bergerak menuju nol. Dan turunannya dimana semua nilai berada pada bagian negatif dan bergerak menuju titik nol.Hal ini menunjukkan bahwa Fungsi Lyapunov dapat dikonstruksi dengan metode Variabel gradien untuk sistem Lorenz pada titik kesetimbangan $\square_{2}$ dengan parameter $\square=24$. Sistem Lorenz pada titik kesetimbangan $\square_{2}$ bersifat stabil.

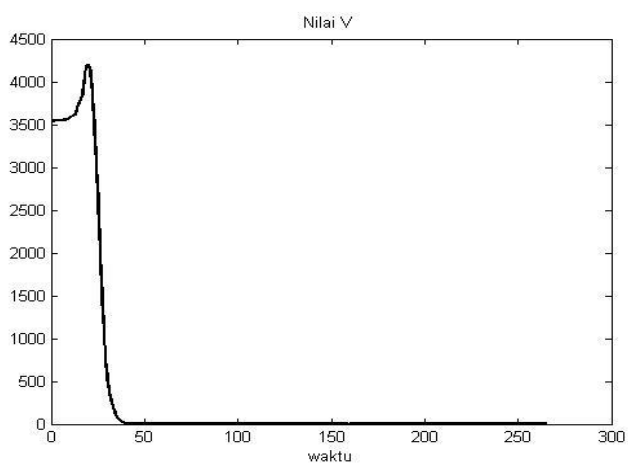

Gambar 9.Grafik Fungsi Lyapunov dengan metode Kravokii 


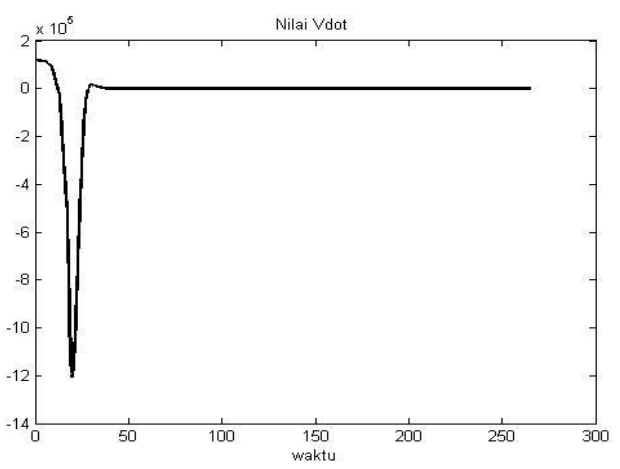

Gambar 10. Grafik Turunan dari gambar 9

Berdasarkan gambar 9 dan 10 terlihat bahwa fungsi Lyapunov semua berada pada nilai negatif dan bergerak menuju titik nol. Dan turunannya dimana nilai berada pada bagian positif dan bergerak menuju titik nol. Hal ini menunjukkan bahwa Fungsi Lyapunov belum dapat dikonstruksi dengan metode Kravoskii untuk sistem Lorenz pada titik kesetimbangan

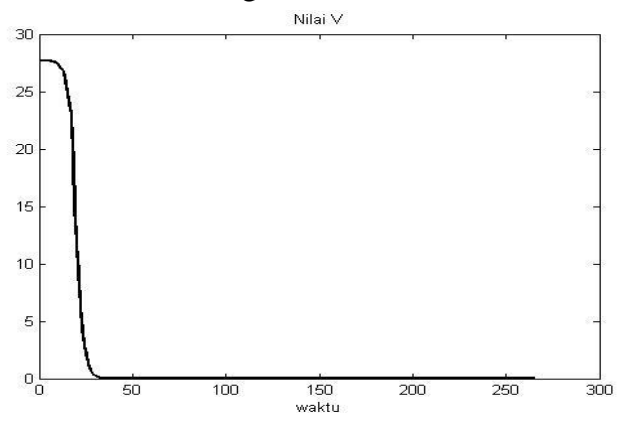

Gambar 11. Grafik Fungsi Lyapunov dengan metode Energi Casimir

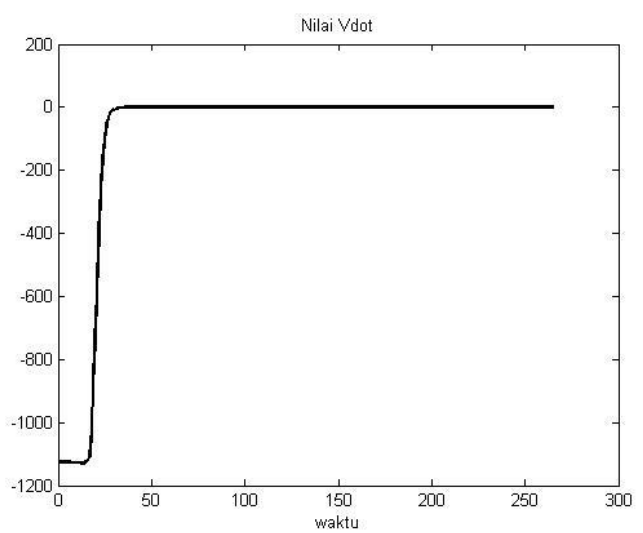

Gambar 12.Grafik turunan gambar 11

Berdasarkan gambar 11 dan 12 terlihat bahwa fungsi Lyapunov semua berada pada nilai positif dan bergerak menuju titik nol. Dan turunan dimana semua nilai berada pada bagian negatif dan bergerak menuju titik nol. Hal ini menunjukkan bahwa Fungsi Lyapunov dapat dikonstruksi dengan metode Energi-Casimir untuk sistem Lorenz pada dua titik kesetimbangan yang lain. Sistem tersebut pada titik kesetimbangan $T_{2}$ bersifat stabil jika $1<r<24.7$.

\section{PENUTUP}

\section{A. Kesimpulan}

1. Sistem pada titik kesetimbangan pada $(0,0,0)$ bersifat stabil local jika $r<1$ dan pada dua titik kesetimbangan yang lain bersifat stabil jika $1<$ $r<\frac{\sigma(\sigma+\beta+3)}{\sigma-\beta-1}$.

2. Sistem Lorenz pada titik kesetimbangan $(0,0,0)$ diperoleh

a. Fungsi Lyapunov dapat dikonstruksi dengan metode variabel gradien.

b. Fungsi Lyapunov belum dapat dikonstruksi dengan menggunakan metode Kravoskii.

c. Fungsi Lyapunov dapat dikonstruksi dengan metode Casimir.

3. Sistem pada dua titik kesetimbangan yang lain.

a. Fungsi Lyapunov dapat dikonstruksi dengan metode variabel gradien. Sistem Lorenz bersifat stabil jika $1<r<$ $\frac{\sigma(\sigma+\beta+3)}{\sigma-\beta-1}$

b. Fungsi Lyapunov belum dapat dikonstruksi dengan menggunakan metode Kravoskii.

c. Fungsi Lyapunov dapat dikonstruksi dengan metode Casimir. Sistem Lorenz bersifat stabil jika $1<r<\frac{\sigma(\sigma+\beta+3)}{\sigma-\beta-1}$

\section{DAFTAR PUSTAKA}

[1] Riyanto, Andi (2015)."Analisis Kestabilan Sistem Suspensi Mobil Seperempat Kendaraan Dengan Metode Lyapunov Langsung”. Skripsi S1, Universitas Islam Negeri Sunan Kalijaga Yogyakarta.

[2] Khalil, H. (2002)."Nonlinear System Third Edition". New Jersey: Pearson Prentice Hall 